\title{
Inflammatory Pathology of the Oral Cavity: Relevance in Oral Oncogenesis
}

\author{
Teresa Sequeira ${ }^{1,2 *}$, Gonçalo Sousa ${ }^{1}$, Eurico Monteiro ${ }^{1,3}$ and Augusta \\ Silveira ${ }^{1,2}$ \\ ${ }^{1}$ Fernando Pessoa University - Health Sciences Faculty, Porto, Portugal \\ ${ }^{2}$ Center for Health Studies and Research of the University of Coimbra and Center for \\ Innovation in Biomedicine and Biotechnology, Coimbra, Portugal \\ ${ }^{3}$ Portuguese Oncology Institute - Porto, Portugal \\ *Corresponding Author: Teresa Sequeira, Associate Professor, Researcher, \\ Fernando Pessoa University - Health Sciences Faculty (UFP-FCS), Portugal.
}

DOI: $10.31080 /$ ASDS.2020.04.0994
Received: October 22, 2020

Published: November 30, 2020

(C) All rights are reserved by Teresa Sequeira., et al.

\section{Abstract}

Oral cancer is considered to be a growing public health problem and within head and neck cancer pathology, it is the most common. It is the 6 th most common cancer in the world, corresponding to approximately $3 \%$ of all cancers.

Despite the dedication and investment in this pathology, the advances in diagnosis strategies and the development of early intervention programs and treatments, aimed to be more targeted, more effective and less aggressive, the global survival rate after 5 years has remained worldwide at approximately $50 \%$ over the last three decades. The evaluation of Quality of Life stands out in this context as a key indicator, along with survival.

We aim to review oral cancer etiology and discuss inflammation role in oral oncogenesis, considering its potential to modulate and amplify the impact of known risk factors. Additionally, we point out inflammation as predictive of poor prognosis in patients with oral cancer or at risk of developing it.

Articles were collected from the PubMed, Bon, Elsevier, Science Direct databases, considering mainly the last 5 years of publication (2015 to 2020). The indexing terms used were "oral oncology and risk factors", "oral oncology and epidemiology" and "inflammation and oncogenesis".

The role of the immune system and inflammation in the initiation, promotion and progression of oncologic pathology of the oral cavity has deserved maximum attention from the scientific community. It is clear that the presence of pro-inflammatory factors associated with immunosuppression are closely related to oral oncogenesis and poor prognosis. The chronic inflammation can contribute to modulate and amplify risk factors actions.

Chronic inflammatory pathology and microbioma of the oral cavity have relevance in oral oncology and can be used as biomarkers, signaling patients at higher risk. There is a whole potential knowledge that can contribute to a better understanding of oral oncogenesis and therefore making it easier both to identify individuals at risk and to achieve more targeted and focused treatment strategies for each cancer patient.

Keywords: Oral Cancer; Risk Factors; Etiology; Quality of Life; Inflammation; Prognosis

\section{Abbreviations}

DNA: Deoxyribonucleic Acid; EBV: Epstein Barr Virus; HPV: Human Papilloma Virus; PMN: Polymorphonuclear Neutrophils; QoL: Quality of Life; SCC: Squamous Cell Carcinoma; TAM: Tumor Associated Macrophages; TM: Tumor Microenvironment.

\section{Introduction}

In a public health context, oncological pathology is not a recent concern. It continues to mobilize increasing resources - whether human, social or economic - in an attempt to find solutions that 
can smooth the path of the cancer patient and his/her caregivers and minimize the negative impacts on the individual, family and society [1-3].

The continuous research and constant reinvention remain the focus of medical science in order to support early diagnosis promotion, the study of how pathologies develop and the impact they have on society and on the quality of life (QoL) of both the patient and relatives. It is aimed to explore new forms of treatment and identify new etiological factors that may trigger, predispose or aggravate already known factors and that might be modified and controlled. There is thus a higher expectation of changing the epidemiological trend of oncology in recent decades [4-6].

In 2018, 18 million new cancer cases were diagnosed worldwide, the most frequent being lung and breast (each with 2.09 million cases), prostate (1.28 million cases) and there were 9 million deaths [7]. Also, in 2018, some 51,600 new cases of oral and pharyngeal cancer were diagnosed in the United States. Despite the dedication and investment in this pathology, the advances in diagnosis strategies and the development of early intervention programs and treatments (aimed to be more targeted, more effective and less aggressive), the global survival rate after 5 years has remained worldwide at approximately $50 \%$ over the last three decades. More specifically, survival after 5 years is only $40 \%$ in Portugal and even lower when only late diagnosed cases are considered, which contrasts with $47 \%$ of the European average. The evaluation of QoL stands out in this context as a key indicator, along with survival $[8,9]$.

We aim to review oral cancer etiology and discuss inflammation role in oral oncogenesis, considering its potential to modulate and amplify the impact of known risk factors. Additionally, we point out inflammation as predictive of poor prognosis in patients with oral cancer or at risk of developing it.

\section{Materials and Methods}

Our research team works on prevention in oral oncology and health-related QoL assessment for 15 years. We formulated questions relating to the identification of risk factors and its interactions, prevalence of chronic inflammatory states in the oral cavity and preventive strategies for head and neck cancer.

Articles were collected from the PubMed, Bon, Elsevier, Science Direct databases, considering mainly the last 5 years of publication
(2015 to 2020). The indexing terms used were "oral oncology and risk factors", "oral oncology and epidemiology" and "inflammation and oncogenesis". We focus on a theoretical basis analysis. Qualitative and quantitative data processing techniques were use and each text was analyzed individually. Due to the limitations pointed out in the revised studies as well as the future perspectives suggested by their authors, several unanswered questions were identified. Perspectives for future research are therefore proposed which highlight the importance of prevention and early diagnosis strategies.

\section{Results}

\section{Oral Oncology around the world: facts}

Oral cancer is considered to be a growing public health problem and within head and neck cancer pathology, it is the most common. It is the $6^{\text {th }}$ most common cancer in the world, corresponding to approximately $3 \%$ of all cancers [10]. All anatomical regions of the oral cavity may be involved: tongue, mouth floor, retromolar trigone, lip, hard palate/soft palate, jugal mucosa and gum. In an epidemiological context, the anatomical region of the nasopharynx, oropharynx and salivary gland tumors are sometimes presented together with the locations of the oral cavity [10].

Squamous cell carcinoma (SCC) is the most prevalent histological type in head and neck oncology, both in developing and developed countries $[11,12]$. Despite advances in diagnosis, surgical and oncologic treatment of SCC, the overall survival rate over 5 years has been maintained over the past three decades at approximately $50 \%$ [10]. According to the World Health Organization, there are an estimated 657,000 new cases of cancer of the oral cavity and pharynx and more than 330,000 deaths each year worldwide $[10,12,13]$.

\section{Oral oncology: from identification of risk factors to prevention strategies}

Several risk factors are associated with oral oncogenesis, such as tobacco and alcohol consumption, as well as infection by several biological agents: Human Papilloma Virus (HPV), Cytomegalovirus, Epstein Barr Virus (EBV), Herpes, Candida and various bacteria. Multiple factors - from genetics to environmental factors such as sun exposure, exposure to harmful chemicals, nutritional factors, chronic oral cavity trauma or even literacy and health education - seem to contribute to oral oncogenesis. All these circumstances are associated with inflammatory states (acute and chronic), considered risk factors for oral oncogenesis and indicators of poor prognosis $[14,15]$. 
The identification of tobacco consumption, in its various forms, as the main risk factor for developing oral cancer has a history of decades. Tobacco consumption is related to $85 \%$ of all malignant head and neck tumors. Oncological pathology develops from the accumulation of mutations in genes involved in cell cycle regulation, angiogenesis, apoptosis, deoxyribonucleic acid (DNA) repair, among others. Approximately 30 to $70 \%$ of malignant head and neck tumors have a p53 gene mutation, a tumor suppressor gene, which has the overall function of preserving the integrity of the genome. The reported variability seems very much associated with ethnicity, geographical location and strongly associated with existing smoking habits. Mutations in the p53 gene can occur as a consequence of exposure to aromatic hydrocarbons, being the benzopyrene found in tobacco among the most carcinogenic. It is therefore not surprising that the risk of developing head and neck cancer pathology is 15 times higher for smokers than for non-smokers $[16,17]$. Premature deaths from tobacco-related oral cancer represent a considerable loss of productivity in developing countries. Furthermore, tobacco consumption is considered to be the second largest cause of death in the world, assuming that it can be the largest avoidable cause of death [18].

The consumption of tobacco combined with alcohol presents a synergistic result, being considered the greatest risk factor in oral carcinogenesis. Excessive alcohol consumption increases the risk of developing oral cancer [16,17]. In 2016, 2.8 million deaths worldwide were associated with alcohol consumption and this consumption contributed to approximately $10 \%$ of deaths at young ages (15-49 years). Epidemiological data show chronic alcohol consumption as a significant risk factor for malignant tumors in several locations: oral cavity, pharynx, larynx, breast, liver, colorectal and lung, being responsible for $5 \%$ of all cancers. The association seems to be greater when related to the development of cancer in the oropharynx and hypopharynx than in the oral cavity and larynx [19-21]. The role of alcohol as a carcinogen is still under discussion - it acts as a co-carcinogen potentiating the carcinogenic effects of other chemicals, acting in the initiation and promotion phase. On the other hand, it is known that ethanol metabolism leads to the emergence of acetaldehyde and free radicals. Several studies show that aldehydes may be responsible for the co-carcinogenicity of alcohol, which, being mutagenic, leads to the inactivation of DNA repair processes, inducing mutations involved in tumor initiation. The consumption of alcohol can result in the exaggerated expression of oncogenes, contributing to the tumor promotion [21,22].

A third risk factor, viral biological agents, has been increasingly involved in oral oncogenesis. It seems such biological agents might be responsible for $5 \%$ of all malignant tumors, as identified in the United States of America and western countries. The HPV is related to an increased risk of head and neck SCC. The subtypes HPV 16 and HPV 18 are considered high risk and the subtypes HPV 6 and HPV 11 are considered low risk. HPV 16 is the predominant subtype found in the oral mucosa and has been the one most related to the group of oncologic pathologies [23].

Table 1 summarizes some of the scientific discussions regarding risk factors related to oral oncogenesis (2015-2020).

\begin{tabular}{|c|c|c|c|}
\hline Risk Factor & Highlighted Evidence & Improvement strategy & Reference \\
\hline Tobacco & $\begin{array}{l}\text { There is a strong association between chewing tobacco and } \\
\text { oral oncogenesis with differences depending on geographi- } \\
\text { cal location - India in the spotlight. } \\
\text { Aetiology influences oncogenesis: it is different when } \\
\text { occurs tobacco/alcohol association, the use of chewing } \\
\text { tobacco or HPV infection. } \\
\text { Malignant tumors have different molecular expression and } \\
\text { clinical-pathological behavior. }\end{array}$ & $\begin{array}{l}\text { Smoking cessation measures and } \\
\text { policies. } \\
\text { Smoking cessation for smokers; } \\
\text { research to understand the basis of } \\
\text { oncogenesis by subgroups. } \\
\text { Margin for optimal diagnosis and } \\
\text { treatment. }\end{array}$ & $\begin{array}{l}{[17]} \\
\text { [17] }\end{array}$ \\
\hline Alcohol & $\begin{array}{l}\text { The risk of all causes of death, specifically cancer, increases } \\
\text { with increased alcohol consumption; consumption that } \\
\text { minimizes health loss is zero. } \\
\text { When alcohol consumption is associated with tobacco } \\
\text { consumption or high-risk genotypes related to dehydro- } \\
\text { genase, the potential for developing oral cancer increases } \\
\text { dramatically. } \\
\text { The risk is greater for heavy consumers for a short period } \\
\text { of time than for light consumers for longer periods. After } \\
20 \text { years of cessation, the risk appears to be similar to } \\
\text { those who have never consumed. }\end{array}$ & $\begin{array}{l}\text { Control measures and policies on } \\
\text { alcohol consumption. } \\
\text { Moderation in alcohol consumption; } \\
\text { Special attention to young popula- } \\
\text { tion. }\end{array}$ & [21] \\
\hline
\end{tabular}




\begin{tabular}{|c|c|c|c|}
\hline Marijuana & $\begin{array}{c}\text { Marijuana contains cannabinoids, immunosuppressants } \\
\text { and potentially mutagenic chemicals. It alters the micro- } \\
\text { biota of the oral cavity and may be associated with cancer } \\
\text { of the oral cavity and pharynx. } \\
\text { Marijuana consumption has been associated with the } \\
\text { development of periodontitis and increases the risk of oral } \\
\text { cancer. }\end{array}$ & $\begin{array}{l}\text { Suspend the consumption of Mari- } \\
\text { juana. } \\
\text { Tight control of periodontal disease } \\
\text { in marijuana consumers. }\end{array}$ & {$[26]$} \\
\hline $\begin{array}{l}\text { Biological Fac- } \\
\quad \text { tors }\end{array}$ & $\begin{array}{c}\text { The oncoprotein HPV E6 (HPV infection) degrades p53 } \\
\text { protein. } \\
\text { The EBV prevalence in various cancers and its ability to } \\
\text { immortalize B cells identifies it as a carcinogenic co-factor } \\
\text { that acts on the progression of the tumor. }\end{array}$ & Vaccination for HPV. & $\begin{array}{l}{[17]} \\
{[27]}\end{array}$ \\
\hline $\begin{array}{l}\text { Nutritional Fac- } \\
\text { tors }\end{array}$ & $\begin{array}{l}\text { The identification of malnutrition high risk patients should } \\
\text { be carried out at diagnosis (risk factor for poor prognosis) } \\
\text { and nutritional support should be included in the treat- } \\
\text { ment of the patient with oral cancer. } \\
\text { The pro-inflammatory potential of the diet is associated } \\
\text { with increased oral and pharyngeal cancer. } \\
\text { Fruit and vegetable consumption are protective; betel } \\
\text { chewing habits (popular in Asia) increase risk. }\end{array}$ & $\begin{array}{l}\text { Healthy diet habits; } \\
\text { nutritional support for oncologic } \\
\text { patients. } \\
\text { Nutritional support for oncologic } \\
\text { patients. }\end{array}$ & $\begin{array}{l}{[28]} \\
{[29]} \\
{[30]}\end{array}$ \\
\hline $\begin{array}{l}\text { Occupational } \\
\text { exposure }\end{array}$ & $\begin{array}{l}\text { There is a strong association between the risk of oral can- } \\
\text { cer and exposure to occupational substances such as: form- } \\
\text { aldehyde, wood dust, asbestos, welding fumes, coal dust, } \\
\text { oil, metals, leather dust, ionising radiation, among others. } \\
\text { Exposure to ionizing radiation increases the risk of oral and } \\
\text { laryngeal cancer. }\end{array}$ & $\begin{array}{l}\text { Use of personal protective equip- } \\
\text { ment; } \\
\text { Respect for the rules of Hygiene and } \\
\text { Safety at Work. } \\
\text { Close surveillance of all those ex- } \\
\text { posed. }\end{array}$ & [32] \\
\hline $\begin{array}{l}\text { Prolonged sun } \\
\text { exposure }\end{array}$ & Prolonged sun exposure is related to lip cancer. & Reduce unprotected sun exposure. & {$[30]$} \\
\hline Chronic Trauma & $\begin{array}{l}\text { Poor oral hygiene and chronic trauma induced by e.g. mal- } \\
\text { adjusted prosthesis, fractured teeth or intra-oral piercing, } \\
\text { increases the risk of oral cancer. }\end{array}$ & $\begin{array}{l}\text { Diagnosis of chronic trauma and } \\
\text { triggering factors removal; biopsy of } \\
\text { suspected lesions. }\end{array}$ & {$[30]$} \\
\hline $\begin{array}{l}\text { Oral Microbiota } \\
\text { and Oral Health }\end{array}$ & $\begin{array}{l}\text { Several bacteria in the oral cavity have been identified as } \\
\text { potential bacterial etiological agents in oral oncogenesis } \\
\text { (Porphyromonas gingivalis, Fusobacterium nucleatum, } \\
\text { Treponema denticola e Streptococcus anginosu). } \\
\text { There is an association between the development of oral } \\
\text { cancer and the oral bacterial community, in particular to } \\
\text { the bacteria associated with periodontitis (Fusobacterium, } \\
\text { Dialister, Peptostreptococcus, Filifactor, Peptococcus, Ca- } \\
\text { tonella, Parvimonas). } \\
\text { Periodontal disease increases the risk of oral cancer. }\end{array}$ & $\begin{array}{l}\text { Bacterial plaque control; control of } \\
\text { oral cavity microbiota. } \\
\text { Control of periodontal disease. } \\
\text { Control of periodontal disease. }\end{array}$ & [35] \\
\hline
\end{tabular}




\begin{tabular}{|c|c|c|c|}
\hline $\begin{array}{l}\text { Genetics and } \\
\text { Heredity }\end{array}$ & $\begin{array}{l}\text { Genetic polymorphisms associated with alcohol consump- } \\
\text { tion need to be further studied to understand the suscepti- } \\
\text { bility of consumers. } \\
\text { Polymorphisms in the MDM2 gene (negative regulator of } \\
\text { p53 gene activity), can increase susceptibility to cancer } \\
\text { development. } \\
\text { Tumour suppressor genes (APC, p53), proto-oncogenes } \\
\text { (Myc), oncogene (Ras) and genes controlling normal } \\
\text { cellular processes (EIF3E, GSTM1) are involved in oral } \\
\text { oncogenesis. } \\
\text { Mutations in proto-oncogenes VAV2 and IQGAP1 have been } \\
\text { associated with family predisposition to develop oral cavity } \\
\text { squamous cell carcinoma. }\end{array}$ & $\begin{array}{l}\text { Cytogenetic and immunocytochemi- } \\
\text { cal control. } \\
\text { Better understanding of the /Un- } \\
\text { derstand the mechanisms of genetic } \\
\text { modification that are responsible for } \\
\text { initiation. }\end{array}$ & $\begin{array}{l}{[17]} \\
{[36]}\end{array}$ \\
\hline $\begin{array}{l}\text { Inflammation } \\
\text { and immune sys- } \\
\text { tem disorders }\end{array}$ & $\begin{array}{l}\text { Inflammation in the tumor microenvironment, whether in- } \\
\text { trinsically or extrinsically acquired, results in immunosup- } \\
\text { pression, increases the risk of malignant transformation, } \\
\text { and stimulates progression and metastization. } \\
\text { Immune system disorders increase the risk of oral cancer. }\end{array}$ & $\begin{array}{l}\text { Self-examination of the oral cavity; } \\
\text { early diagnosis and control of inflam- } \\
\text { matory pathology of the oral cavity } \\
\text { by health professionals. } \\
\text { Cytogenetic and immunocytochemi- } \\
\text { cal control. }\end{array}$ & [39] \\
\hline
\end{tabular}

Table 1: Risk factors related to oral oncogenesis (2015-2020).

In the broad scientific discussion that we are currently witnessing, the various risk factors arise interlinked and inflammation seems to be the common denominator, standing out as the factor closely related to the initiation, promotion and progression of malignant neoplasms.

Inflammatory pathology of the oral cavity: its relevance in oral oncology

Relations between inflammation and the tumor microenvironment

Head and neck cancers are highly inflammatory in nature. Chronic inflammatory oral lesions show some degree of malignant potential in association with the development of SCC, including leukoplakia, erythroplasia, lichen planus and submucosal fibrosis. Metanalysis reveals a positive association between periodontal disease and risk of oral cancer, supporting the interaction of chronic inflammation and cancer progression. These risk factors imply that oral inflammation is an important component of oral SCC progression $[15,40]$.
Although SCCs have always been considered as gene-related diseases, the molecular, genetic and immunoregulatory mechanisms of carcinogenesis remain unclear. As chronic inflammation is usually associated with worse prognosis, it is essential to understand how the tumor microenvironment (TM) is involved in the progression of SCC $[15,41]$. The interaction between tumors and their immunological microenvironment is complex and difficult to decipher [15]. TM, heavily influenced by chronic inflammation, has been shown to play a decisive prognostic role in the progression of oral cancer probably due to interference of the specific molecular microenvironment for cancer cells [15]. The inflammatory infiltrate, together with the inflammatory mediators, play an essential role in the formation of TM suitable for the expansion of tumor cells. The inflammation can be intrinsically derived from the tumor cells themselves - associated with the accumulation of mutations - or associated with several other factors such as viral infection, fungal or bacterial infection, autoimmune diseases, obesity, tobacco and alcohol consumption, exposure to asbestos, among others. Such mechanisms, intrinsic and extrinsic, both with inflammatory 
potential occur in all phases of the tumor development, from oncogenesis to metastization, triggering mechanisms for tumor plasticity and progression $[39,40,42]$. Recent evidence indicates that oral tumors exist as a transformed complex of tumor cells, complexed with other cells that constitute the oral TM associated with SCC [43].

\section{Macrophages associated with tumors}

In recent years, several studies have found that macrophages comprise up to $50 \%$ of the mass of malignant solid tumors and play a decisive role in the infiltration of immune cells in the tumor $[44,45]$. Most tumor associated macrophages (TAM) are differentiated from monocytes derived from bone marrow. TAM exhibit great versatility as immune cells, as they produce several factors in TM that may promote or inhibit tumor progression [46]. It has been demonstrated that TAMs regulate cancer-related inflammation, immune response, matrix remodeling, and metastasizing capacity [47]. In addition, TAMs activate several molecular targets and signaling pathways related to the tumor formation process, including proliferation, apoptosis, invasion migration and angiogenesis. It was found that TAMs in SCC promote the formation of new tumors through the production of cytokines and pro-inflammatory factors that play a critical role in the various stages of malignant transformation, including growth, survival, invasion, angiogenesis and metastasis [43].

Unlike macrophages in non-cancerous tissues, TAMs are modified by the tumor, losing part of their phagocytic and effective antigen presentation capacity to $\mathrm{T}$ cells. Thus, TAMs present cellular plasticity in response to local microenvironmental stimuli. Macrophages are functionally heterogeneous cells, influenced by numerous signals present in TM that contributes to its instruction and polarization and therefore potentially influencing the development and progression of SCC. Furthermore, mitogen activated kinetic proteins can regulate inflammation and a wide range of cellular processes, including metabolism, proliferation, motility, apoptosis, survival, differentiation. Mitogen activated kinetic proteins play thus a crucial role in cellular growth and survival in several physiological and pathological processes, including innate processes and adaptive immune responses [15].

\section{The role of Polymorphonuclear Neutrophils}

Polymorphonuclear neutrophils (PMNs) are the most abundant leukocytes $( \pm 60 \%$ ) in blood circulation and evolved as specialized cells capable of killing invading microorganisms. PMNs are present on all mucosal surfaces and constantly migrate to the oral cavity to maintain balance [48].

In contrast to other members of the innate immune system, its potential for heterogeneity has not received much attention. Classically, PMNs are terminally differentiated cells in the blood and are considered a homogeneous population. PMNs exhibit unique properties, with a relatively short life span, absence of proliferative capacity, production capacity of reactive oxygen species and limited cytokine release capacity [49]. However, in the last decade, evidence on the phenotypic heterogeneity of peripheral circulation PMNs has emerged $[50,51]$. Subsets of PMNs were differentiated based on their phenotypic characteristics and their antimicrobial activity capacity [52]. Since the oral cavity consists of a combination of healthy oral tissue sites and stimulated oral tissue (e.g. sites with inflammation), the heterogeneity of PMNs therefore seems highly likely in the oral cavity [53]. In addition to the various states of activation in the tissue, the subsets of oral PMNs may also be different based on their migration route and access to the oral cavity (migration by chemotactic, mechanical or other sources such as tonsils [53]. It is still unclear whether different subsets are also associated with different functional responses.

The literature shows an unequivocal association between the inflammatory process and the initiation, promotion and progression phases in oncology. It is also clear the long way science has to go for a wider understanding of the mechanisms involved in both genesis and tumor progression that can thus be the result of unique, individual combinations. Such understanding is promising to optimize early diagnosis and therapeutic strategies, more focused on the uniqueness of each oncologic patient.

\section{Discussion}

This section discusses the relevance of inflammatory pathology of the oral cavity in the context of oral cancer.

Retrospective studies have evaluated histological diagnoses after biopsy of lesions present in the oral cavity. The results are diverse and the following stand out: epithelial hyperplasia/inflammatory fibrous hyperplasia (the most frequently diagnosed), fibroma, granuloma, ulcerative lesion, lichen planus/lichenoid reaction, papilloma; keratosis, cyst, mucocellum, dysplastic lesion and squamous cell carcinoma (representing approximately $2 \%$ of the total histological results of biopsies performed) [54,55]. 
According to several authors, reactive hyperplastic lesions represent between $10.7 \%$ - $41.6 \%$ of the universe of oral pathology, analyzing the histological features of biopsies, Dutra and collaborators published in 2019 a study of 534 cases of reactive hyperplastic lesions, in a range of 2,400 records, corresponding to $22.5 \%$ of all diagnoses [54]. They represent a group of oral pathologies considered benign, which presents an exophytic shape and firm and fibrous consistency and results from a chronic inflammatory response to low intensity stimulus, which involves the constant repair of tissues. They include fibrous inflammatory hyperplasia (in $70 \%$ of all cases), fibromas and granulomas and are found preferentially in the gingiva/alveolar ridge, jugal mucosa, lip and tongue. They are associated with smoking habits, the use of poorly adjusted prostheses, trauma of the oral mucosa due to parafunctional habits, poor oral hygiene, fractured dental pieces, root remains or teeth that have sharp edges, the presence of brackets, implants or oral piercing $[54,56,57]$. These studies show that coexistence with lesions of an inflammatory nature of the oral cavity is a reality in the practice of Dentistry.

Additionally, oral microbioma has received a lot of attention in the context of oral medicine. It is known that the binomial inflammation/infection is associated with $25 \%$ of all cancers, creating mutations in the DNA, such as 8-oxo-7,8-dihydro-2'-desoxyganosine (8-oxodG) and 8-nitroguanine. Viruses like HPV, EBV or cytomegalovirus are associated with oral oncogenesis. Common bacteria in the oral cavity universe, especially associated with inflammatory/ infectious periodontal disease - which include the periopathogens Porphyromonas gingivalis, Fusobacterium nucleatum, Treponema denticola and Streptococcus anginosus - have been associated with the induction of chronic inflammation, inhibition of apoptosis, increased cell proliferation, suppression of the immune system and release of carcinogenic substances. Karpinski, in 2019 corroborates this association and indicates the bacteria Streptococcus sp., Peptostreptococcus sp., Prevotella sp., Fusobacterium sp., Porphyromonas gingivalis, and Capnocytophaga gingivalis as strongly associated with the development of oral cancer [58]. He points to the release of inflammatory chemical mediators as facilitators of proliferation, mutagenesis, oncogenic activation and angiogenesis [58-60]. This association is so important that the presence of oral bacteria has been indicated in recent decades as biomarkers of specific types of cancer: Porphyromonas gingivalis stands out in the signaling of gum cell carcinoma, or Streptococcus intermedius, S. constellatus, $S$. oralis, S. mitis, S. sanguis, S. salivarius, Peptostreptococcus sp., in the case of oral mucosa cancer $[58,61,62]$.
The role of the immune system and immune cells in particular, in association with the secretion of chemical mediators of inflammation is not fully clarified, but has been linked to initiation, promotion and progression in oncology, and specifically to oral cancer.

Inflammatory cytokines such as interleukins $-1 \beta$ (IL-1 $\beta$ ), IL6, IL-17, IL-23, tumor necrosis factor alpha (TNF $\alpha$ ) and matrix metalloproteinases such as MMP-8 and MMP-9 have been associated. Monocyte/macrophage inflammatory cells, neutrophils, fibroblasts and mast cells are also related. IL-1 $\beta$ is associated to the stimulation of vascular endothelial growth factor production, promoting an inflammatory microenvironment, potentiating angiogenesis and tumor progression [58,63].

It is known that the inflammation associated with TM can have an intrinsic origin (mutated cells promote the recruitment of inflammatory cells) or extrinsic (infection, chronic trauma, autoimmune disease, obesity, tobacco or alcohol consumption, occupational exposure, among others). It seems clear that coexistence with pro-inflammatory factors as diverse as exposure to asbestos, nanomaterials or the presence of inflammatory pathology such as oral leukoplakia, promotes mutation and predisposes to oral cancer $[39,59]$. It has become clear that the topic stands out today in oncology.

There is still a long way to go, but the authors here reviewed agree that inflammation has the potential to modulate and amplify the impact of known risk factors. There is a whole potential knowledge that can contribute to a better understanding of oral oncogenesis and therefore making it easier both to identify individuals at risk and to achieve more targeted and focused treatment strategies for each cancer patient.

\section{Conclusions}

We highlight as conclusions of this work:

- The role of the immune system and inflammation in the initiation, promotion and progression of oncologic pathology of the oral cavity has deserved maximum attention from the scientific community. It is clear that the presence of pro-inflammatory factors associated with immunosuppression are closely related to oral oncogenesis and poor prognosis.

- The chronic inflammation can contribute to modulate and amplify risk factors actions.

- Chronic inflammatory pathology and microbioma of the oral cavity have relevance in oral oncology and can be used as biomarkers, signaling patients at higher risk. 
- $\quad$ Participation of Oral Sciences in all phases of oncologic patient follow-up is crucial to modify epidemiological trends and optimize patients' and their relatives' QoL.

\section{Conflict of Interest}

The authors declare that there is no financial interest or conflict of interest.

\section{Bibliography}

1. Kahriman Fatma and Ayten Zaybak. "Caregiver Burden and Perceived Social Support among Caregivers of Patients with Cancer". Asian Pacific Journal of Cancer Prevention: APJCP 16.8 (2015): 3313-3317.

2. Kassianos Angelos P., et al. "The impact of specialized palliative care on cancer patients' health-related quality of life: a systematic review and meta-analysis". Supportive Care in Cancer: official Journal of the Multinational Association of Supportive Care in Cancer 26.1 (2018): 61-79.

3. Ren Zhen-Hu., et al. "Global and regional burdens of oral cancer from 1990 to 2017: Results from the global burden of disease study". Cancer Communications (London, England) 40.2-3 (2020): 81-92.

4. Schwingshackl Lukas., et al. "Adherence to Mediterranean Diet and Risk of Cancer: An Updated Systematic Review and MetaAnalysis". Nutrients 9.10 (2017).

5. Silveira Augusta., et al. "Head and Neck Cancer: Improving Patient-Reported Outcome Measures for Clinical Practice". Current Treatment Options in Oncology 19.11 (2018): 59.

6. Lewandowska Anna Maria., et al. "Environmental risk factors for cancer - review paper". Annals of Agricultural and Environmental Medicine: AAEM 26.1 (2019): 1-7.

7. Mattiuzzi Camilla and Giuseppe Lippi. "Current Cancer Epidemiology". Journal of Epidemiology and Global Health 9.4 (2019): 217-222.

8. Epstein Joel B and Pelin Güneri. "The adjunctive role of toluidine blue in detection of oral premalignant and malignant lesions". Current Opinion in Otolaryngology and Head and Neck Surgery 17.2 (2009): 79-87.

9. Sequeira, Teresa., et al. "10-Year Experience: Routine Assessment of Health-Related Quality of Life in Head and Neck Cancer Patients". Global Journal of Otolaryngology 12.2 (2017).

10. Ghantous Yasmine and Imad Abu Elnaaj. "Global incidence and risk factors of oral cancer”. Harefuah 156.10 (2017): 645-649.
11. Siegel Rebecca L., et al. "Cancer statistics, 2020". CA: a Cancer Journal for Clinicians 70.1 (2020): 7-30.

12. Ferlay Jacques., et al. "Cancer incidence and mortality worldwide: sources, methods and major patterns in GLOBOCAN 2012". International Journal of Cancer 136.5 (2015): E359386.

13. World Health Organization.

14. Hsiao Jenn-Ren., et al. "The interplay between oral microbiome, lifestyle factors and genetic polymorphisms in the risk of oral squamous cell carcinoma". Carcinogenesis 39.6 (2018): 778-787.

15. Li Zhen-Ning., et al. "The p38/MKP-1 signaling axis in oral cancer: Impact of tumor-associated macrophages". Oral Oncology 103 (2020): 104591.

16. Varshney PK., et al. "Tobacco and alcohol consumption in relation to oral cancer". Indian Journal of Otolaryngology and Head and Neck Surgery: Official Publication of the Association of Otolaryngologists of India 55.1 (2003): 25-28.

17. Patel K R., et al. "Clinical implications of p53 alterations in oral cancer progression: a review from India". Experimental Oncology 40.1 (2018): 10-18.

18. Chaturvedi Pankaj., et al. "Tobacco related oral cancer". BMJ (Clinical research ed.) 365 (2019).

19. GBD 2016 Alcohol Collaborators. "Alcohol use and burden for 195 countries and territories, 1990- 2016: a systematic analysis for the Global Burden of Disease Study 2016". Lancet 392 (2018): 1015-1035.

20. Kawakita Daisuke and Keitaro Matsuo. "Alcohol and head and neck cancer". Cancer Metastasis Reviews 36.3 (2017): 425-434.

21. Varoni Elena M., et al. "Ethanol versus Phytochemicals in Wine: Oral Cancer Risk in a Light Drinking Perspective". International Journal of Molecular Sciences 16.8 (2015): 17029-17047.

22. Pöschl G and H K Seitz. "Alcohol and cancer". Alcohol and Alcoholism (Oxford, Oxfordshire) 39.3 (2004): 155-165.

23. Korzeniewski Nina., et al. "Genomic instability and cancer: lessons learned from human papillomaviruses". Cancer Letters 305.2 (2011): 113-122.

24. Asthana Smita., et al. "Association of smokeless tobacco with oral cancer: A review of systematic reviews". Tobacco Prevention and Cessation 5 (2019): 34. 
25. Newman Taylor M.., et al. "Microbiomic differences at cancerprone oral mucosa sites with marijuana usage". Scientific Report 9 (2019): 12697.

26. Ortiz Ana P., et al. "Association of marijuana use with oral HPV infection and periodontitis among Hispanic adults: Implications for oral cancer prevention". Journal of Periodontology 89.5 (2018): 540-548.

27. Guidry J T., et al. "Epstein-Barr virus in the pathogenesis of oral cancers". Oral Diseases 24.4 (2018): 497-508.

28. Silva Joaquim Castro., et al. "Head and Neck Cancer Early Identification of Malnutrition High Risk Patients and Quality of Life Optimization". International Journal of Otolaryngology and Head and Neck Surgery 8 (2019): 204-216.

29. Shivappa Nitin., et al. "Inflammatory potential of diet and risk of oral and pharyngeal cancer in a large case-control study from Italy". International Journal of Cancer 141.3 (2017): 471479.

30. Cancer. Net. [Online].

31. Awan Kamran Habib., et al. "Oral and pharyngeal cancer risk associated with occupational carcinogenic substances: Systematic review". Head and Neck 40.12 (2018): 2724-2732.

32. Richardson David B., et al. "Site-specific Solid Cancer Mortality After Exposure to Ionizing Radiation: A Cohort Study of Workers (INWORKS)". Epidemiology (Cambridge, Mass.) 29.1 (2018): 31-40.

33. Zhang Yangheng., et al. "Human oral microbiota and its modulation for oral health". Biomedicine and Pharmacotherapy = Biomedecine and Pharmacotherapie 99 (2018): 883-893.

34. Zhao Hongsen., et al. "Variations in oral microbiota associated with oral cancer". Scientific Reports 7.1 (2017): 11773.

35. Karmakar Shaswata., et al. "Periodontitis and oral Cancer-A striking link”. Oral Oncology 106 (2020): 104630.

36. Ali Johar., et al. "Genetic etiology of oral cancer". Oral Oncology 70 (2017): 23-28.

37. Huang,Y., et al. "Identification of novel genetic variants predisposing to familial oral squamous cell carcinomas". Cell Discovery 5 (2019): 57.

38. Al-Kaabi Rasha., et al. "Social inequalities in oral cancer literacy in an adult population in a multicultural deprived area of the UK". Journal of Public Health 38.3 (2015).
39. Singh Nitin., et al. "Inflammation and cancer". Annals of African Medicine 18.3 (2019): 121-126.

40. Kim Jaehong and Jong-Sup Bae. "Tumor-Associated Macrophages and Neutrophils in Tumor Microenvironment". Mediators of Inflammation 2016 (2016): 6058147.

41. Xiao Meng., et al. "M1-like tumor-associated macrophages activated by exosome-transferred THBS1 promote malignant migration in oral squamous cell carcinoma". Journal of Experimental and Clinical Cancer Research: CR 37.1 (2018): 143.

42. Vergara Daniele., et al. "The Cancer Microbiota: EMT and Inflammation as Shared Molecular Mechanisms Associated with Plasticity and Progression". Journal of Oncology (2019): 1253727.

43. Peltanova B., et al. "Effect of tumor microenvironment on pathogenesis of the head and neck squamous cell carcinoma: a systematic review". Molecular Cancer 18.63 (2019): 1-24.

44. Van Overmeire Eva., et al. "Mechanisms driving macrophage diversity and specialization in distinct tumor microenvironments and parallelisms with other tissues". Frontiers in Immunology 5 (2014): 127.

45. Sousa S., et al. "Human breast cancer cells educate macrophages toward the M2 activation status". Breast Cancer Research: BCR 17 (2015): 101.

46. Coussens Lisa M and Zena Werb. "Inflammation and cancer". Nature 420.6917 (2002): 860-867.

47. Schmieder Astrid., et al. "Differentiation and gene expression profile of tumor-associated macrophages". Seminars in Cancer Biology 22.4 (2012): 289-297.

48. Rijkschroeff Patrick., et al. "Oral polymorphonuclear neutrophil characteristics in relation to oral health: a cross-sectional, observational clinical study". International Journal of Oral Science 8.3 (2019): 191-198.

49. Amulic Borko., et al. "Neutrophil function: from mechanisms to disease". Annual Review of Immunology 30 (2012): 459-489.

50. Silvestre-Roig Carlos., et al. "Neutrophil heterogeneity: implications for homeostasis and pathogenesis". Blood 127.18 (2016): 2173-2181.

51. Leliefeld Pieter HC., et al. "Differential antibacterial control by neutrophil subsets”. Blood Advances 2.11 (2018): 1344-1355. 
52. Hellebrekers Pien., et al. "Neutrophil phenotypes in health and disease". European Journal of Clinical Investigation 48.2 (2018): e12943.

53. Rijkschroeff Patrick., et al. "Oral Polymorphonuclear Neutrophil Contributes to Oral Health". Current oral Health Reports 5.4 (2018): 211-220.

54. Dutra Kamile Leonardi., et al. "Incidence of reactive hyperplastic lesions in the oral cavity: a 10 year retrospective study in Santa Catarina, Brazil”. Brazilian Journal of Otorhinolaryngology 85.4 (2019): 399-407.

55. Melo Auremir Rocha., et al. "Prevalência de lesões bucais diagnosticadas no laboratório de patologia bucal da Universidade Tiradentes (2002-2010)/Prevalence of oral lesions diagnosed in oral pathology laboratory of Tiradentes University (20022010)". Revista de Cirurgia e Traumatologia Buco-maxilo-facial 13.2 (2013): 109-114.

56. Vidyanath Surendran., et al. "Reactive hyperplasic lesions of the oral cavity: A survey of 295 cases at a Tertiary Health Institution in Kerala". Journal of Oral and Maxillofacial Pathology: JOMFP 19.3 (2015): 330-334.

57. Kashyap Bina., et al. "Reactive lesions of oral cavity: A survey of 100 cases in Eluru, West Godavari district". Contemporary Clinical Dentistry 3.3 (2012): 294-297.

58. Karpiński Tomasz M. "Role of Oral Microbiota in Cancer Development”. Microorganisms 7.1 (2019): 20.

59. Murata Mariko. "Inflammation and cancer". Environmental Health and Preventive Medicine 23.1 (2018): 50.

60. Zhang Wei-long., et al. " Who Is Who in Oral Cancer?" Experimental Cell Research 15.384 (2019): 111634.

61. Sakamoto, Haruo., et al. "Isolation of bacteria from cervical lymph nodes in patients with oral cancer". Archives of Oral Biology 44.10 (1999): 789-793.

62. Katz Joseph., et al. "Presence of Porphyromonas gingivalis in gingival squamous cell carcinoma”. International Journal of Oral Science 3.4 (2011): 209-215.

63. Scheff Nicole N., et al. "Tumor necrosis factor alpha secreted from oral squamous cell carcinoma contributes to cancer pain and associated inflammation". Pain 158.12 (2017): 23962409.

\section{Assets from publication with us}

- Prompt Acknowledgement after receiving the article

- Thorough Double blinded peer review

- Rapid Publication

- Issue of Publication Certificate

- High visibility of your Published work

Website: www.actascientific.com/

Submit Article: www.actascientific.com/submission.php

Email us: editor@actascientific.com

Contact us: +919182824667 